This document was prepared in conjunction with work accomplished under Contract No. DE-AC09-96SR18500 with the U.S. Department of Energy.

This work was prepared under an agreement with and funded by the U.S. Government. Neither the U. S. Government or its employees, nor any of its contractors, subcontractors or their employees, makes any express or implied: 1 . warranty or assumes any legal liability for the accuracy, completeness, or for the use or results of such use of any information, product, or process disclosed; or 2 . representation that such use or results of such use would not infringe privately owned rights; or 3 . endorsement or recommendation of any specifically identified commercial product, process, or service. Any views and opinions of authors expressed in this work do not necessarily state or reflect those of the United States Government, or its contractors, or subcontractors. 
WSRC-STI-2006-00220

Revision 0

\title{
A Quick Key to the Subfamilies and Genera of Ants of the Savannah River Site, Aiken, SC
}

\author{
By F. Douglas Martin \\ Environmental Analysis Section \\ Environmental Sciences and Bio Technology Department \\ Savannah River National Laboratory
}

This taxonomic key was devised to support development of a Rapid Bioassessment Protocol using ants at the Savannah River Site. The emphasis is on "rapid" and, because the available keys contained a large number of genera not known to occur at the Savannah River Site, we found that the available keys were unwieldy. Because these keys contained more genera than we would likely encounter and because this larger number of genera required both more couplets in the key and often required examination of characters that are difficult to assess without higher magnifications (60X or higher) more time was required to process samples. In developing this set of keys I recognize that the character sets used may lead to some errors but I believe that the error rate will be small and, for the purpose of rapid bioassessment, this error rate will be acceptable provided that overall sample sizes are adequate. Oliver and Beattie (1996a, 1996b) found that for rapid assessment of biodiversity the same results were found when identifications were done to morphospecies by people with minimal expertise as when the same data sets were identified by subject matter experts. Basset et al. (2004) concluded that it was not as important to correctly identify all species as it was to be sure that the study included as many functional groups as possible. If your study requires high levels of accuracy, it is highly recommended that when you key out a specimen and have any doubts concerning the identification, you should refer to keys in Bolton (1994) or to the other keys used to develop this area specific taxonomic key.

The list of genera to be included was developed starting with Van Pelt and Gentry (1985), and then adding genera from Deyrup (2003), Deyrup et al. (1989); Graham et al. (2004b) and Ipser et al (2004). This key is based on a number of ant identification keys in the general literature but the ones that I used most in developing it were: Bolton (1994); Graham et al. (2004a); McGown (date uncertain); Plowes and Patrock (2000), Van Pelt and Gentry (1985); and Mackay and Mackay (date uncertain)

One feature used in this key that is not common to all taxonomic keys is the tracking number which is a bold blue number at the left margin at each key couplet. This number refers to the previous key couplet that directed you to this particular couplet. This is used to backtrack when it appears that you have arrived at a particular key couplet by error.

Unless otherwise noted, all photographs were done by the author. 


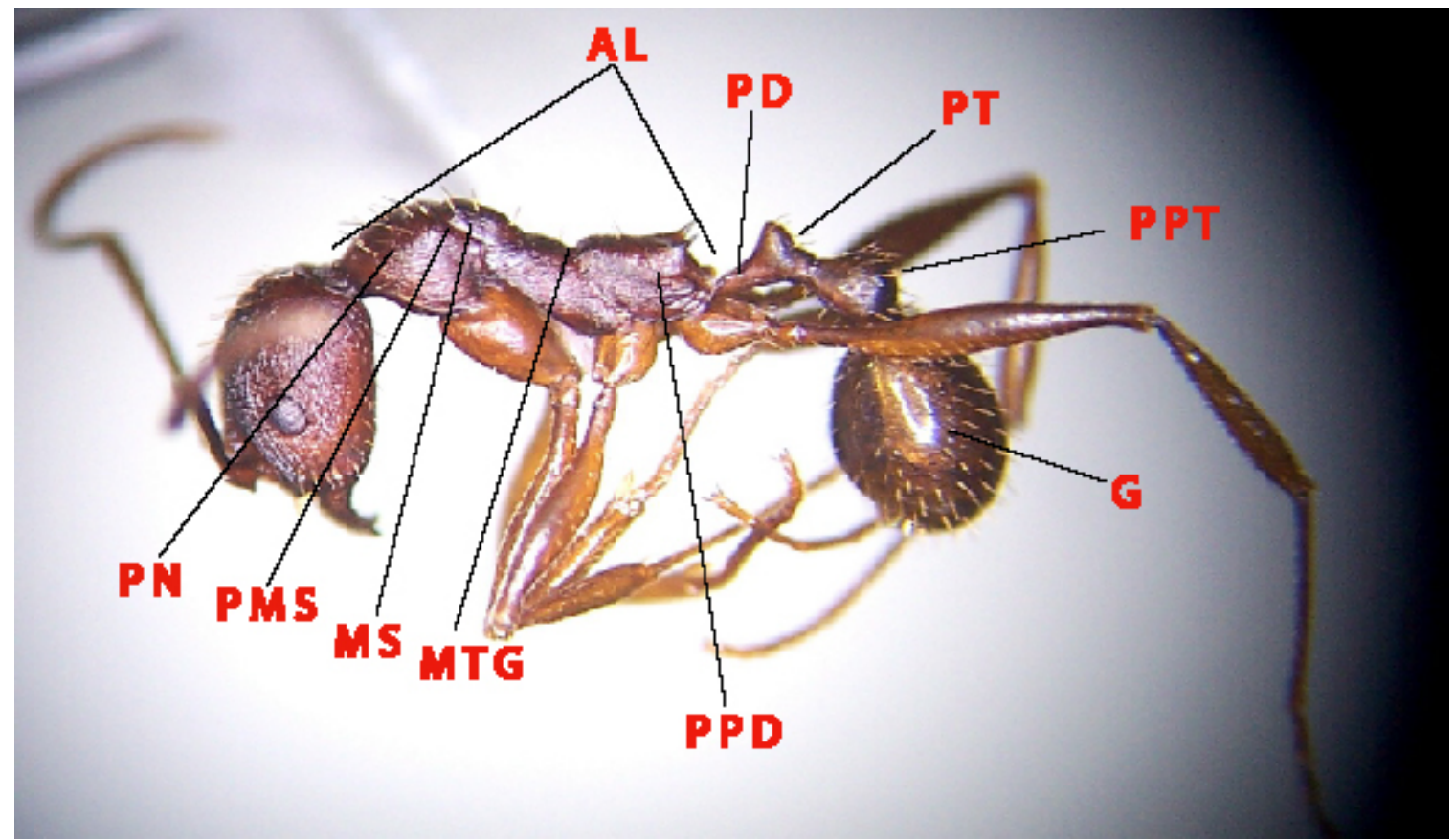

Figure 1. Important landmarks on an ant body. $A L=$ alitrunk; $\mathrm{G}=$ gaster; $\mathrm{MS}=$ mesonotum; $\mathrm{MTG}=$ metanotal groove; $\mathrm{PD}=$ peduncle of petiole; $\mathrm{PMS}=$ promesonotal suture; $\mathrm{PN}=$ pronotum; $\mathrm{PPD}=$ propodeum; $\mathrm{PPT}=$ postpetiole; $\mathrm{PT}$ $=$ petiole

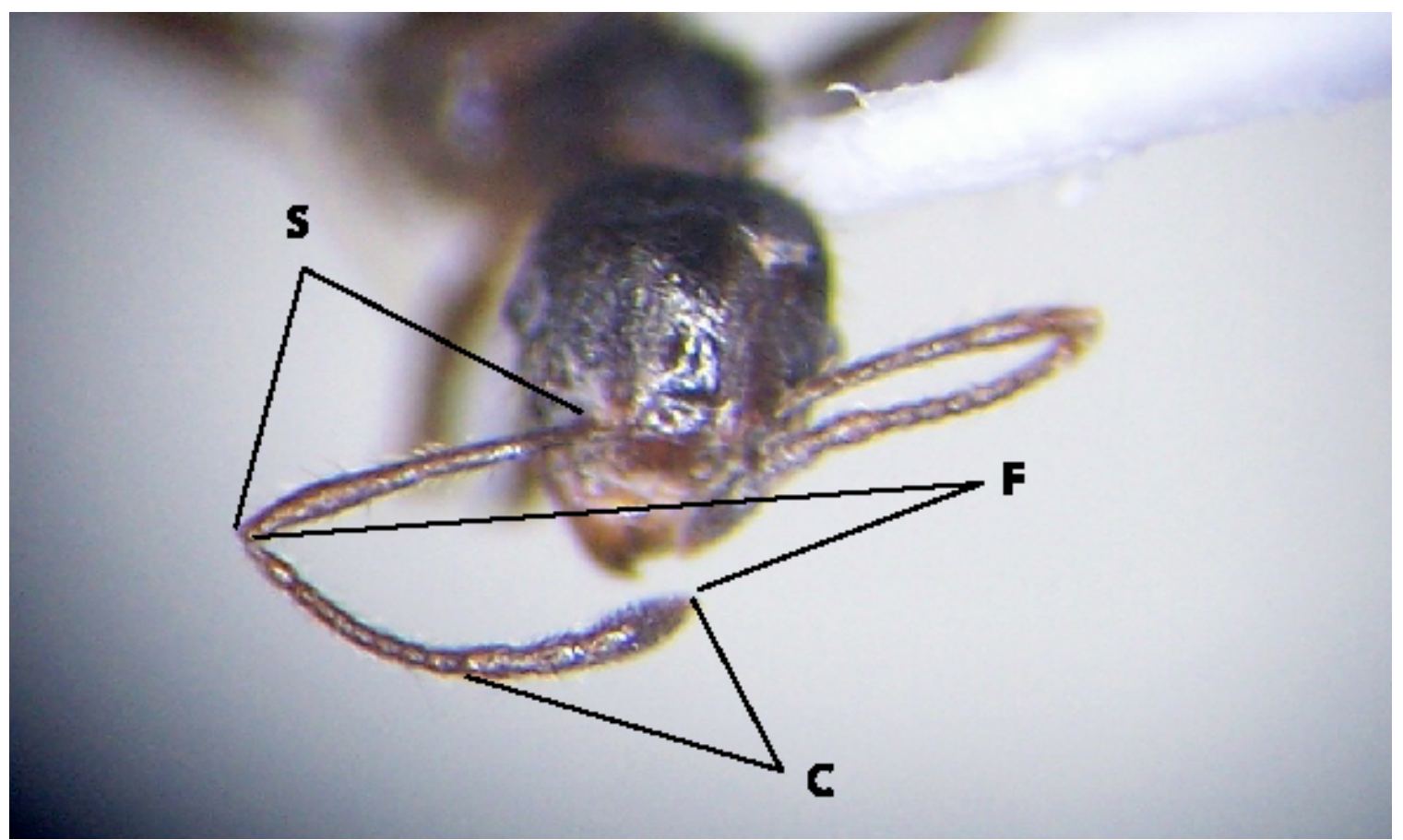

Figure 2. Parts of the antenna. $\mathrm{C}=$ club; $\mathrm{F}=$ funniculus; $\mathrm{S}=$ scape 


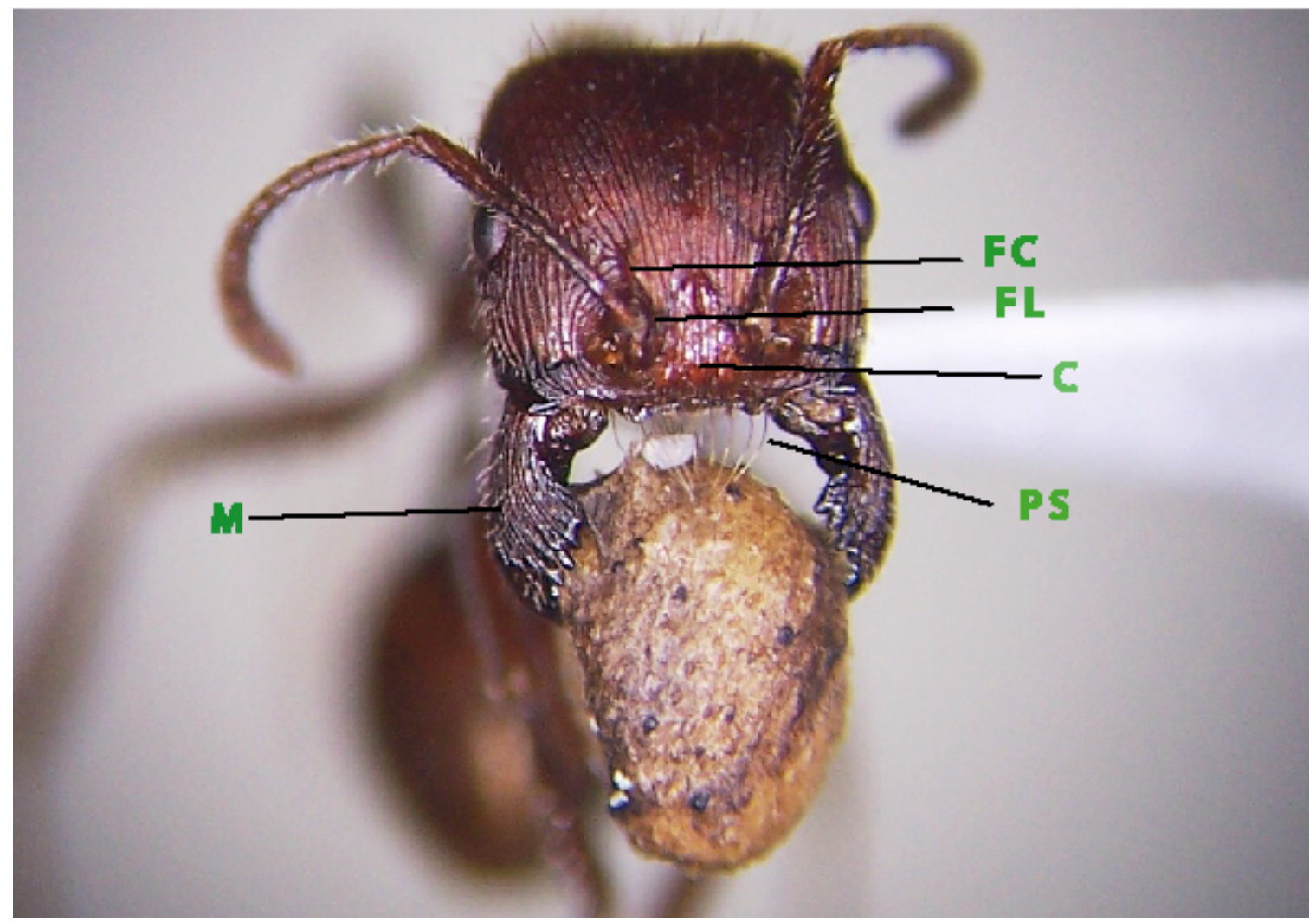

Figure 3. Parts of the face often referred to. $\mathrm{C}=$ clypeus; $\mathrm{FC}=$ frontal carina; $\mathrm{FL}$ = frontal lobe; $M=$ mandible; $P S=$ psammophore (rarely seen from this angle)

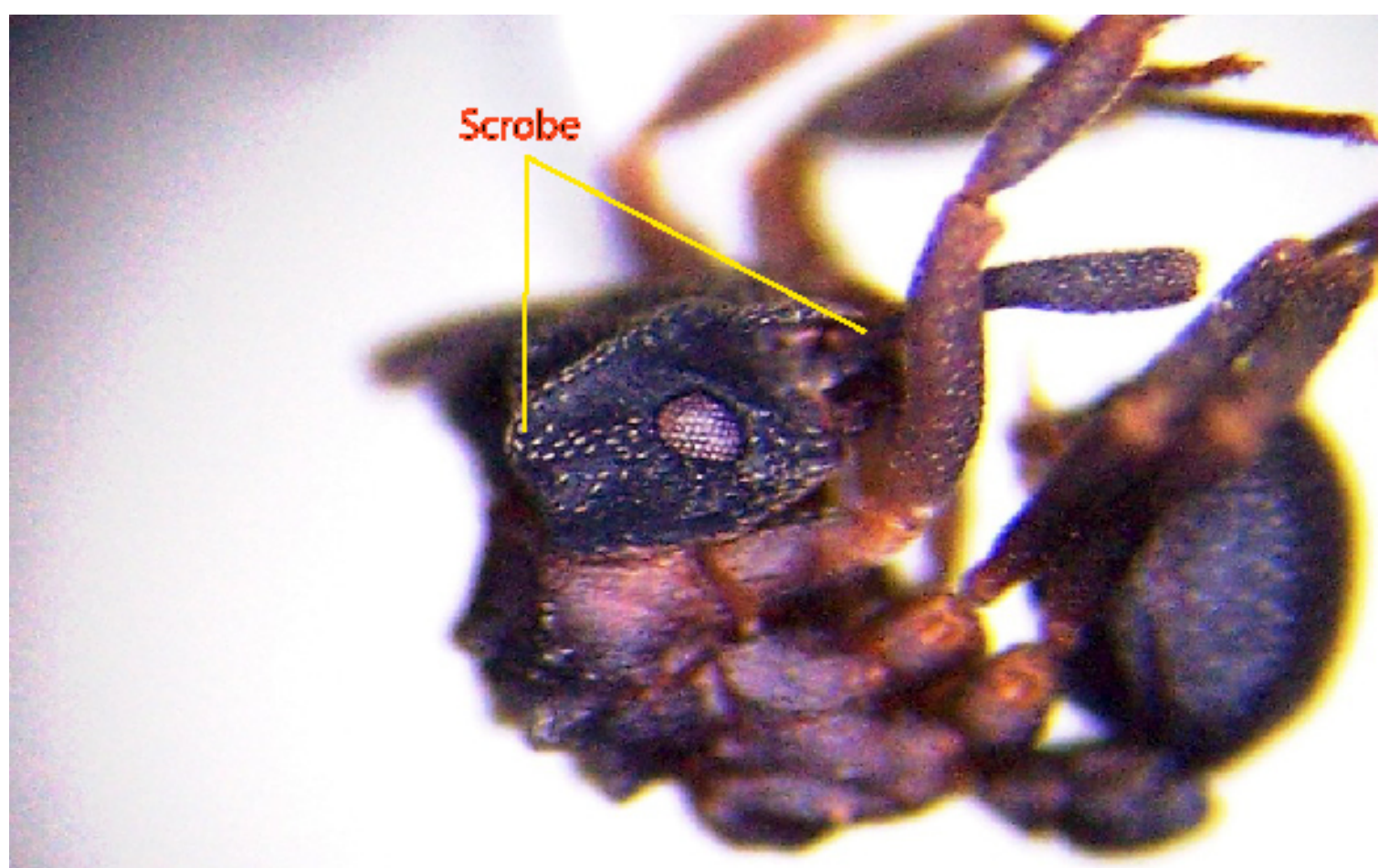

Figure 4. Showing the typical location of the scrobe. 


\section{Key to the Subfamilies of Local Ants}

1A Body with a single reduced or isolated segment (the petiole) between alitrunk and gaster (Figure 5) ................................. 2 1B Body with two reduced or isolated segments (the petiole and postpetiole) between alitrunk and gaster (Figure 6) 5

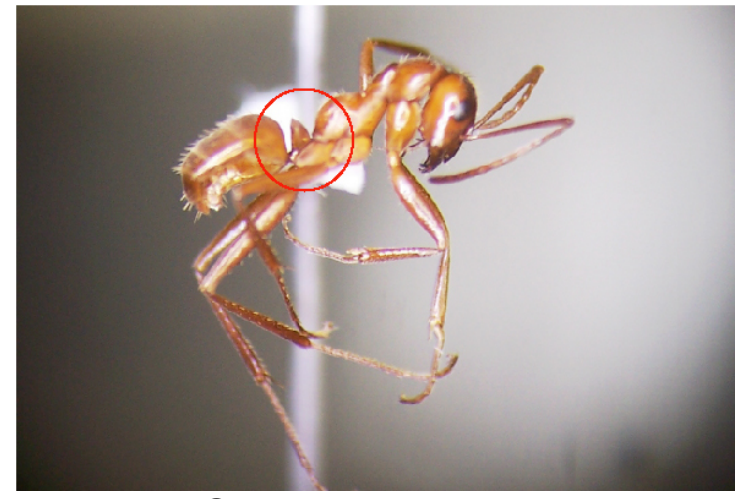

Figure 5. Single segment between alitrunk and gaster.

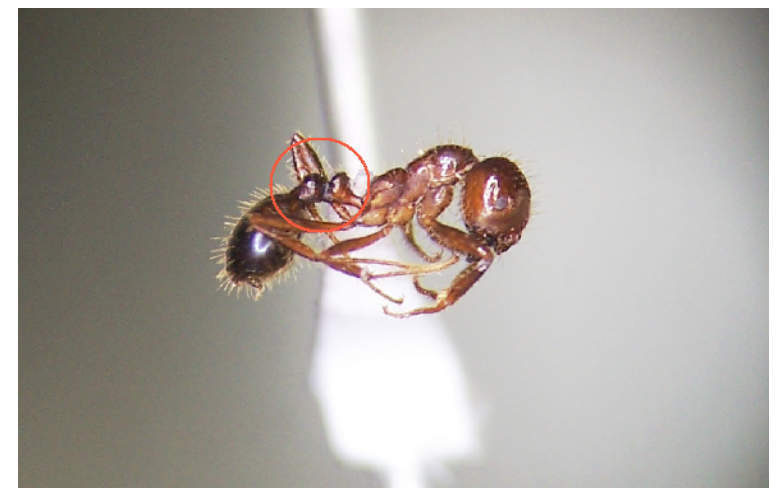

Figure 6. Two segments between alitrunk and gaster.

12 Apex of gaster with a semicircular or circular acidophore formed from the hypopygium (last lower plate of the gaster), this structure often projecting as a nozzle and fringed with setae; if the acidophore is concealed by a projection of the pygidium the antennal origins are well behind the posterior clypeal margin; sting absent (Figure 7)

Formicinae page 10

2B Apex of gaster lacking an acidophore; sting present or absent (Figure 8).....

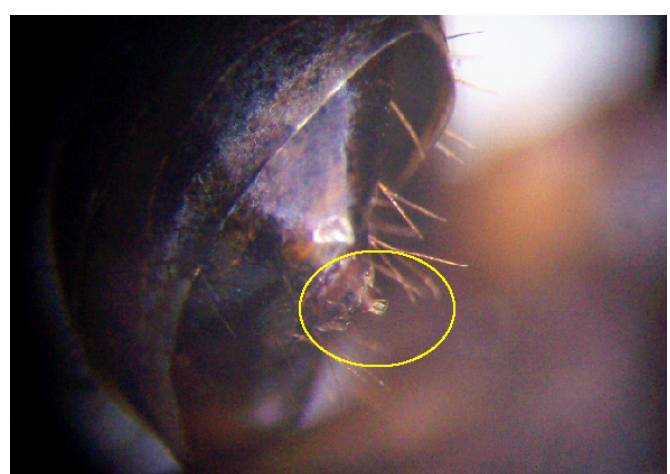

Figure 7. Location and appearance of an acidophore.

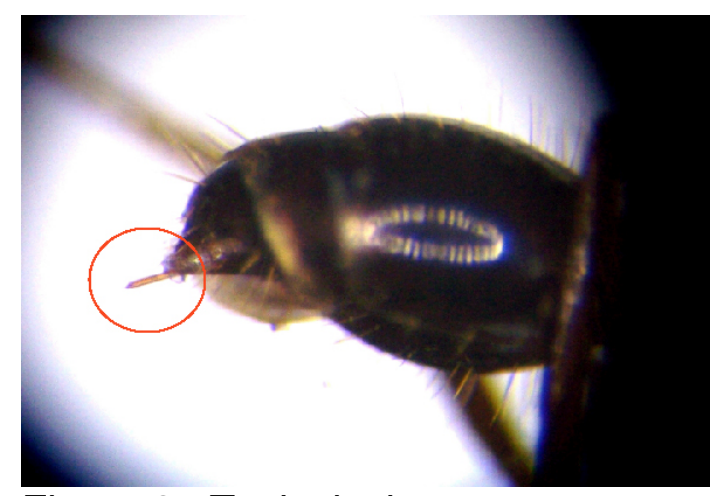

Figure 8. Typical sting. 
23 A Gaster with a noticeable constriction between first and second segment (Figure 9) .......................... Ponerinae (in part) page 19 3B Gaster lacking a constriction between first and second segment (Figure 10)

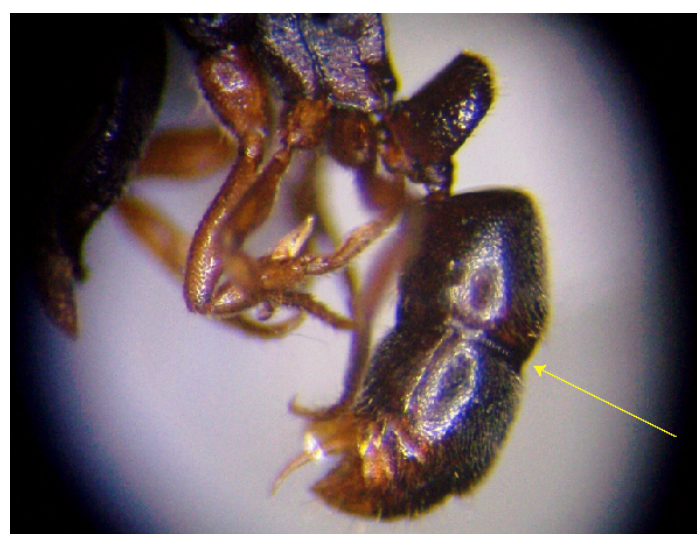

Figure 9. Constriction between first and second gastral segment.

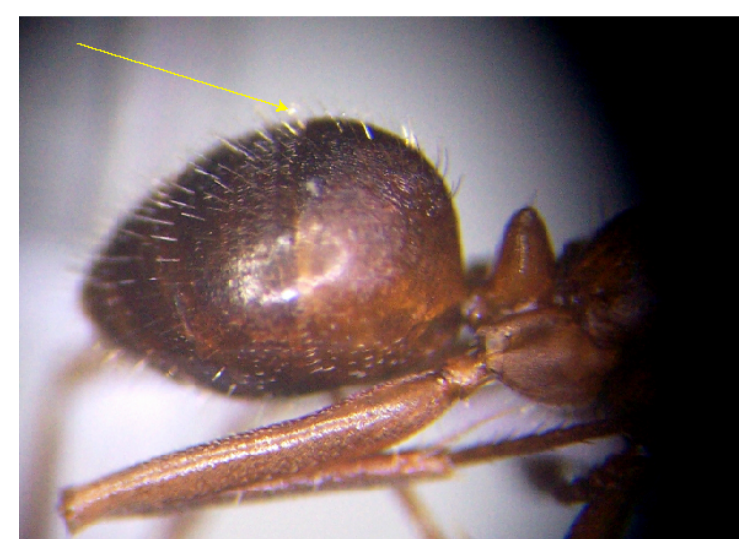

Figure 10. Lack of constriction between first and second gastral segment.

34 Sting absent or vestigial; if present requires dissection to see; a difficult to see slit-like opening where the sting or acidophore would be ................................................ Dolichoderinae page 8 4B Sting present and functional, often projecting in dead specimens; in many species sting shaft visible through the cuticle even with fully retracted; no such slit-like opening present if sting not visible Ponerinae (in part) page 19 
$15 \mathrm{~A} \quad$ Frontal lobes either absent or very reduced and vertical; antennal sockets completely open and not concealed by frontal lobes in full-face view (Figure 11)

5B Frontal lobes present, horizontal to somewhat elevated; antennal sockets partly concealed by the frontal lobes in full-face view (Figure 12)

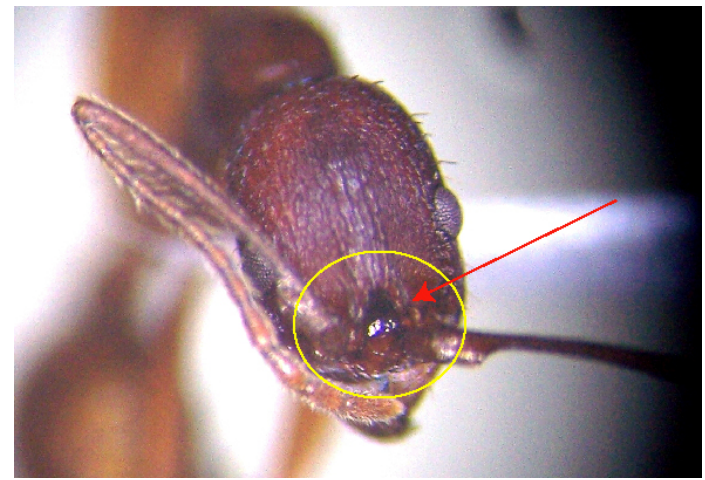

Figure 11. Frontal lobes not expanded to hide insertions of antennae and mandibles.

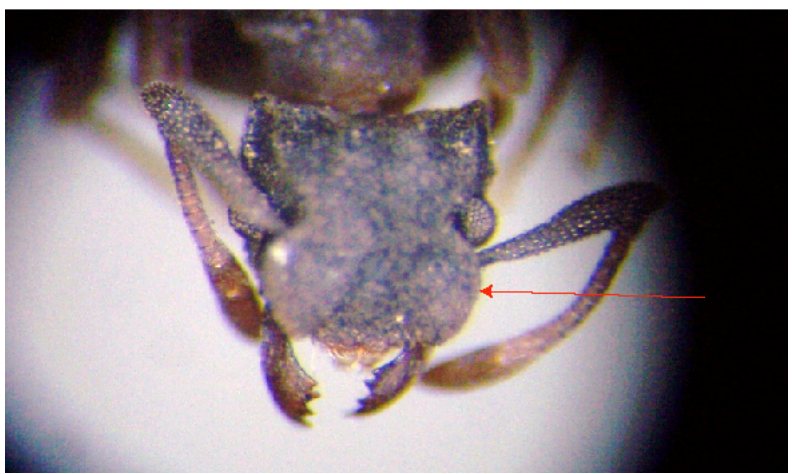

Figure 12. Frontal lobes expanded, hiding insertions of antennae and mandibles.

56 A Eyes present and conspicuous, with many ommatida 7

6B Eyes absent or present only as a single ommatidium or small featureless blister ÉEcitoninae

$6 \quad 8 \mathrm{~A} \quad$ Hind tibia with a conspicuous pectinate apical spur. Posterior margin of median portion of clypeus not projecting back between antennal sockets (Figure 13). Promesonotal suture present. Antenna always with 12 segments................................ ${ }^{\text {? Pseudomyrmecinae (in part) }}$ 8B Hind tibia without a conspicuous pectinate apical spur, spur either simple or (more frequently) absent. Posterior margin of median portion of clypeus projecting back between antennal sockets (Figure 14). Promesonotal suture present or absent. Antenna usually with fewer than 12 segments. Myrmicinae (in part) page 12 


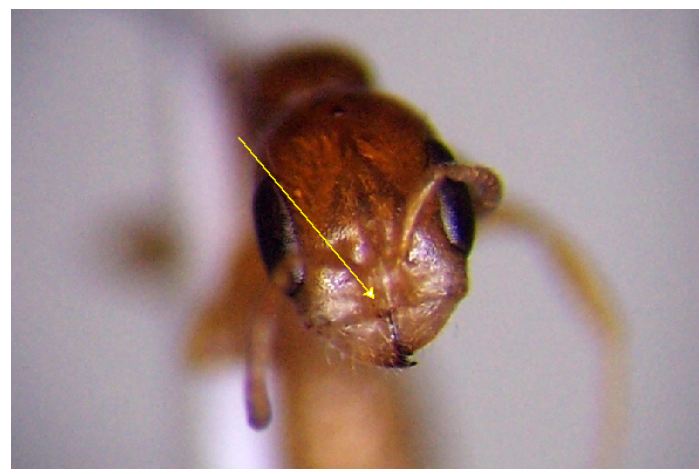

Figure 13. Posterior margin of clypeus not extending between bases of antennae.

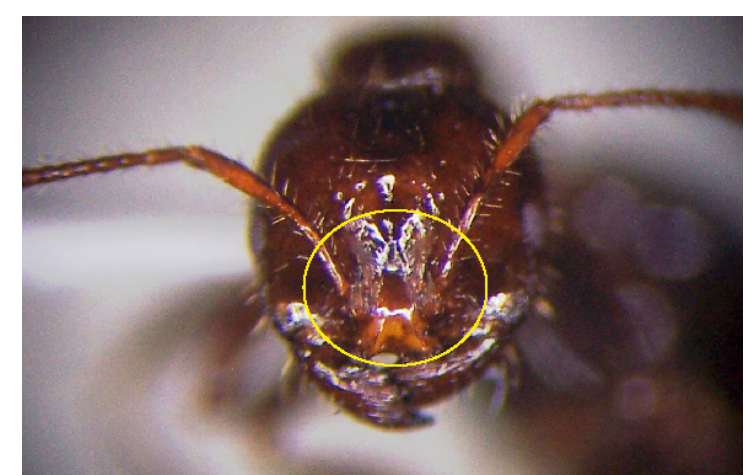

Figure 14. Posterior margin of clypeus extending between and separating bases of antennae.

$7 \quad 9$ A Posterior margin of median portion of clypeus straight to weakly arcuate and more or less level with anterior margins of antennal sockets, median portion of clypeus not projecting strongly backward between antennal sockets (Figure 13). ................ ${ }^{2}$ Pseudomyrmecinae (in part)

9B Posterior margin of median portion of clypeus arcuate to triangular and extending well behind the level of the anterior antennal sockets, thereby separating them (Figure 14). Myrmicinae (in part) page 12

\footnotetext{
${ }^{1}$ Neivamyrmex is the sole genus of Ecitoninae in our region; some authorities place this genus in the Old World subfamily Dorylinae.

${ }^{2}$ Pseudomyrmex is the sole genus of Pseudomyrmecinae in our region.
} 


\section{Key to the Local Dolichoderine Ants}

1A Petiole reduced to a simple, flattened strip when seen in profile, never with a standing scale or node; first gastral segment projects over the petiole and petiole not visible from above (Figure 15). .................. 2 1B Petiole with a node or scale when seen in profile, node may be high and erect, or lower and inclined forward; gaster may or may not project over the petiole (Figure 16).

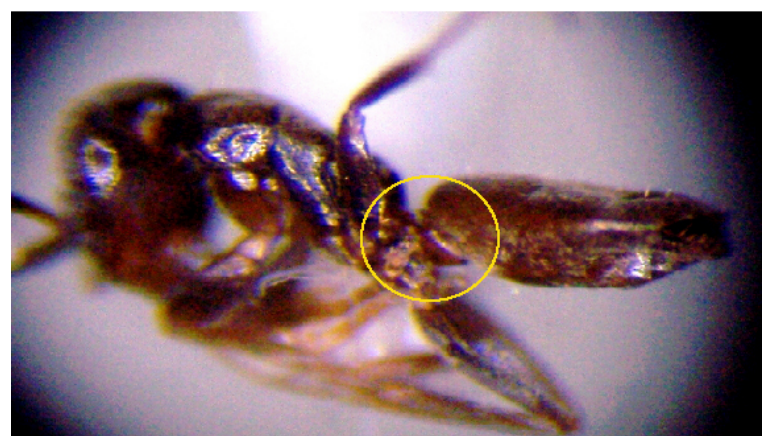

Figure 15. Petiole simple, strap-like with no standing scale or node.

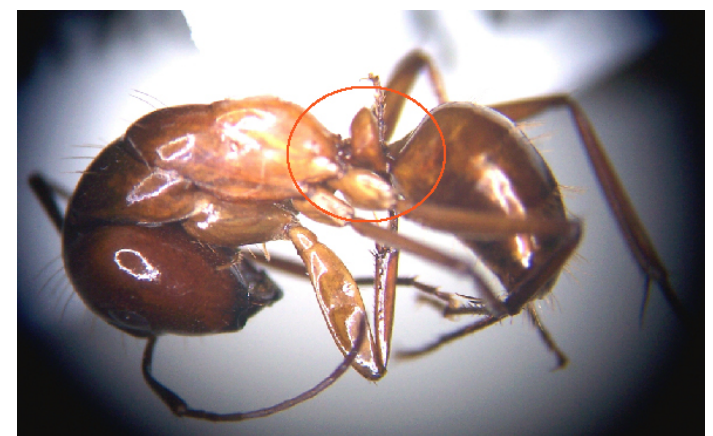

Figure 16. Petiole with a standing scale or node.

$12 \mathrm{~A}$ Only 4 gastral tergites visible in dorsal view, the fifth tergite is reflected below the fourth and visible in ventral view; no erect hairs present on dorsum of alitrunk. Tapinoma 2B Five gastral tergites visible in dorsal view; erect hairs present on dorsum of alitrunk. Technomyrmex

$13 \mathrm{~A}$ Integument hard, thick and strongly sculptured; head with foveolate punctures; hypostoma with tooth-like prominance on each side anterolaterally; propodeal declivity strongly concave. Dolichoderus 3B Integument thin, weakly sculptured, but can be dense; no foveolate punctures on head; no tooth-like prominance on hypostoma; propodeal declivity not concave.

34 Central anterior clypeal margin concave. 5

4B Central anterior clypeal margin straight or convex. 6

$4 \quad 5 \mathrm{~A} \quad$ Petiolar scale vertical, not inclined anteriorly and reaching upwards almost to the level of the propodeum. Ochetellus 5B Petiolar scale inclined anteriorly and reaching upwards almost to the level of the propodeum. *Linepithema 
$56 \mathrm{~A}$ In profile, propodeum has a single raised tooth or spine extending from the angle between the dorsum and the declivity (Figure 17); in fullface view the clypeal setae project forward beyond the apices of the closed mandible; psammophore present; apical mandibular tooth enlarged and much larger than preapical tooth. Dorymyrmex 6B In profile, propodeum may be angular, but never extending into a tooth or spine (Figure 18); head in full-face view not having clypeal setae projecting forward over apices of closed mandibles; psammophore not present; apical mandibular tooth only slightly larger than preapical tooth. Forelius

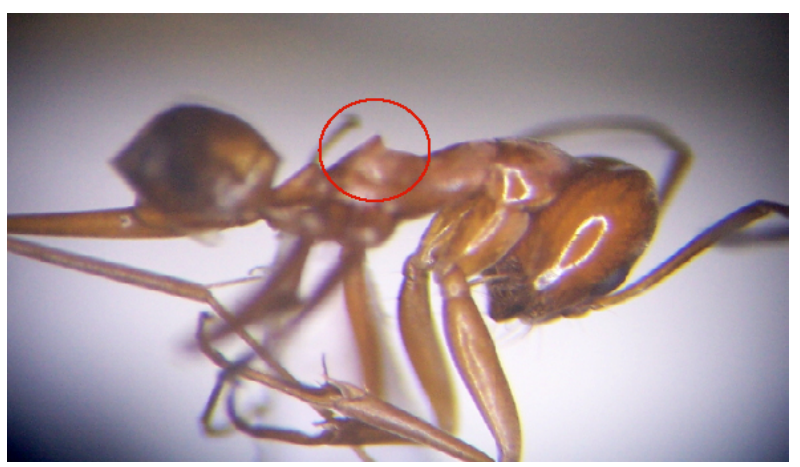

Figure 17. Propodeum with a single raised point or spine.

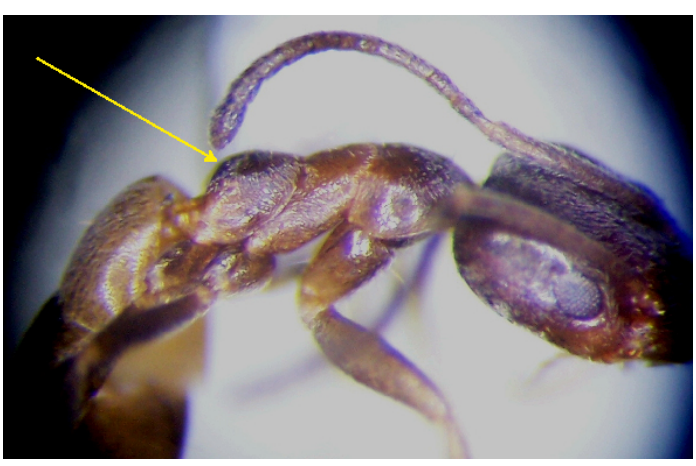

Figure 18. Propodeum angular but with no raised point or spine.

*Used species characters for this key couplet so that only L. humile will definitely separate out in this key couplet but this introduced species is the only species of this genus currently reported for the continental U.S. 


\section{Key to the Local Formicine Ants}

$1 \mathrm{~A}$ Antenna with 12 segments.

2

1B Antenna with 9 segments.

Brachymyrmex

$12 \mathrm{~A} \quad$ Profile of alitrunk continuous and evenly convex; antennae inserted well above the dorsal border of the clypeus (Figure 19); metapleural gland orifice absent, the surface of the metapleuron uninterrupted by a gland orifice above the hind coxa and below the level of the propodeal spiracle, guard setae for metapleural gland absent. .................... Camponotus 2B Profile of alitrunk not continuous and evenly convex, the propodeum distinctly depressed below the level of the mesonotum, mesoepinotal suture always distinct, often deep; antennae inserted at or near the dorsal border of the clypeus (Figure 20); metapleuron with a distinct, wide orifice for the metapleural gland, orifice of metapleural gland usually protected by a line or tuft of guard setae.

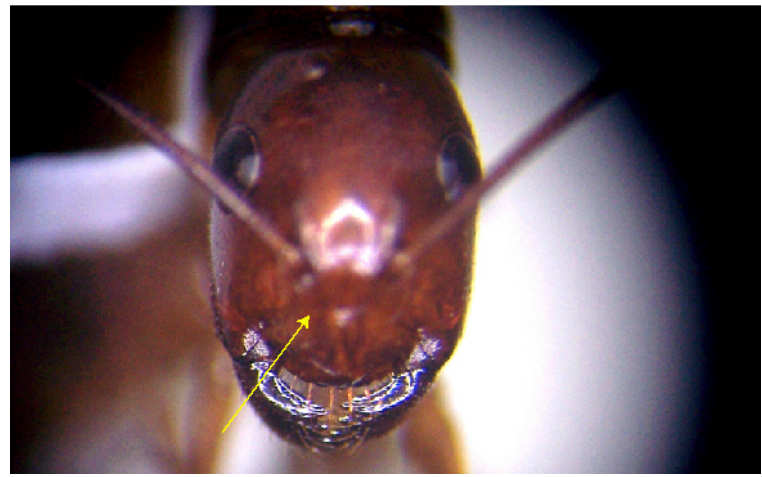

Figure 19. Arrow marks posterior margin of clypeus.

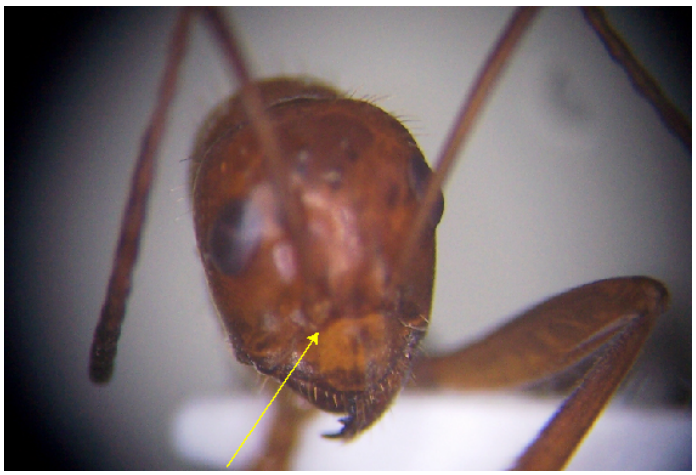

Figure 20. Antennal base next to clypeus margin.

$23 \mathrm{~A} \quad$ Mandibles sickle-shaped and edentate; palp formula

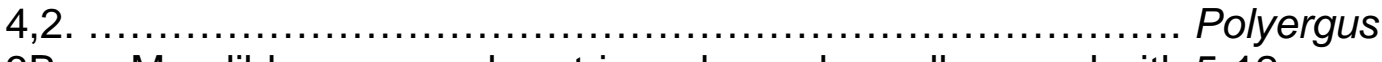

3B Mandibles more or less triangular and usually armed with 5-12 sharp teeth of varying size; palp formula usually 6,4 or 3,3, but never

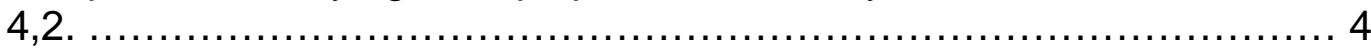

34 Frontal carinae short but distinct, each a small ridge with a moderately to sharply angulate summit that is sometimes slightly reflected upward; ocelli conspicuous (Figure 21); with gaster in ventral view the first sternite with a conspicuous transverse sulcus behind the helcium; propodeal spiracle elliptical to broadly oval. Formica 
4B Frontal carinae indistinct or absent, if present, each carina is a small ridge with a distinctly rounded summit; ocelli small or absent (Figure 22); with gaster in ventral view the first sternite without a transverse sulcus behind the helcium; propodeal spiracle circular to subcircular.

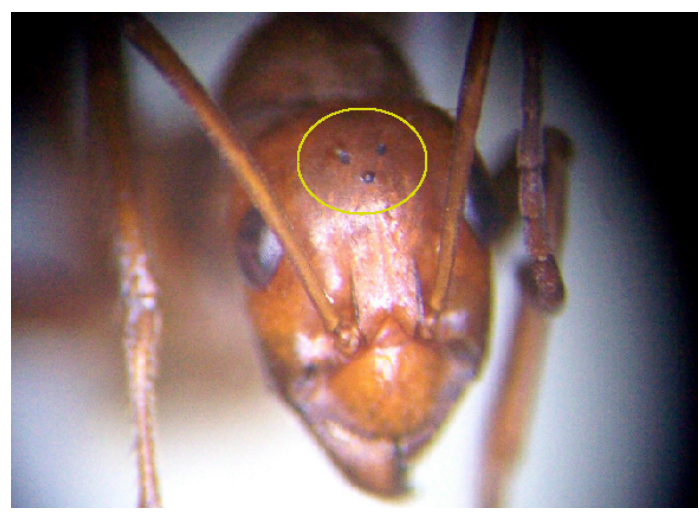

Figure 21. Cluster of three ocelli visible on upper head surface.

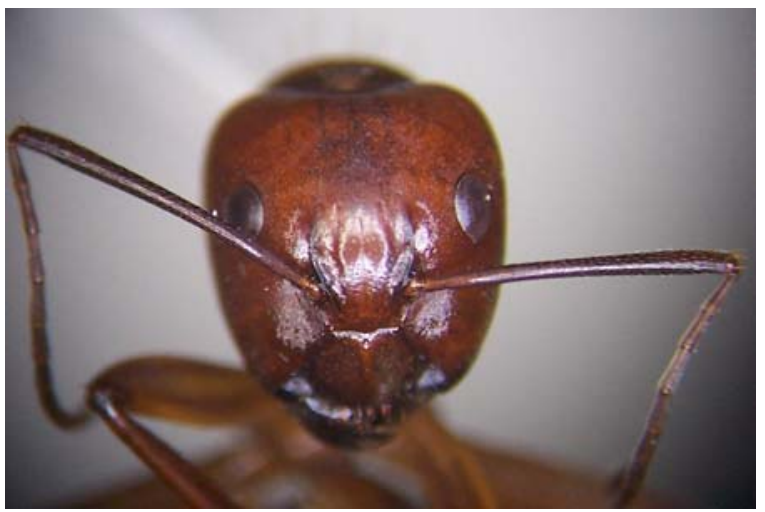

Figure 22. No obvious ocelli present on upper head surface.

$4 \quad 5 \mathrm{~A} \quad$ Mandibles with at least 7 teeth; antennal scapes passing the occipital border by no more than 2-3 times maximum diameter of the scape, usually less.

5B Mandibles with 5 or 6 teeth; antennal scapes frequently passing the occipital border by 4 or 5 times the maximum diameter of the scape or more.

56 6 Maxillary palps 3 segmented and extremely short, palp formula 3,3 . Acanthomyops 6B Maxillary palps 6 segmented and moderately short to long, palp formula 6,4 . Lasius

5 7A Mesonotum weakly constricted with alitrunk lacking obvious hourglass shape; with head in full-face view the eyes at or in front of the midlength of the sides; dorsal surface of head and body with coarse setae that may be arranged in distinct pairs. Paratrechina 7B Mesonotum in dorsal view severely constricted giving the alitrunk a distinctive hour-glass shape; with head in full-face view the eyes behind the midlength of sides; pilosity not conspicuously coarse or bristle-like; erect hairs mostly slender and golden or brownish. Prenolepis

Myrmelachista ramulorum, an introduced Caribbean arboreal species from this subfamily, has been reported for Florida but not Georgia or South Carolina. It has not been included in this key but might eventually work its way northward. 


\section{Key to the local Myrmicine Ants}

1A Antennae with ten or less segments. ........................... 2

1B Antennae with more than ten segments. ....................... 5

$12 \mathrm{~A} \quad$ Antenna with 7 or fewer segments. .............................. 3 2B Antenna with 10 segments. .............................. Solenopsis

2 3A Antenna with 4-6 segments; antennal scrobe present or absent but, if present, running over eye. ......................................... 4 3B Antenna with 7 segments; antennal scrobes running below the eye. Eurhopalothrix

34 Mandibles long, thin and linear with an apical fork of 2 or 3 spinelike teeth (Figure 23). Strumigenys 4B Mandibles triangular to subtriangular, if long and thin, no apical fork (Figure 24).......... Epitritus, Pyramica or Smithistruma - these all may be synonyms

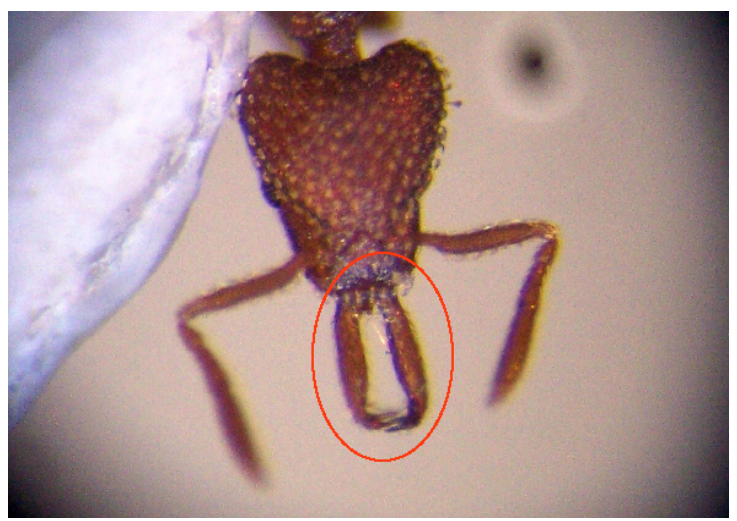

Figure 23. Long, linear mandibles with an apical fork of 2 or 3 teeth.

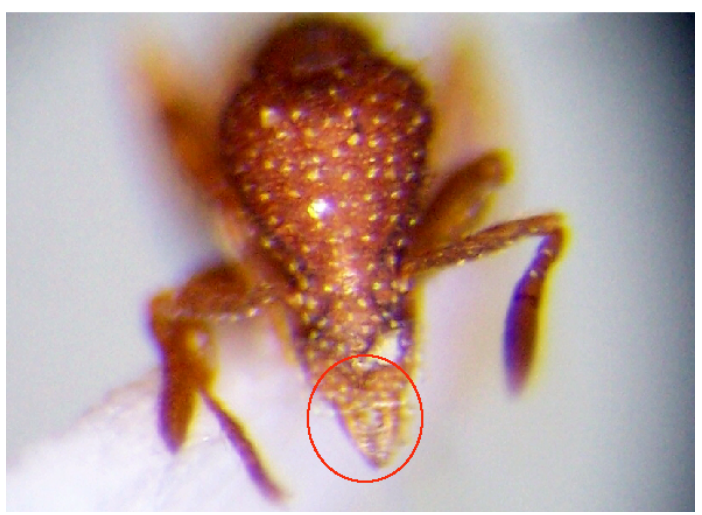

Figure 24. Mandibles long but not having an apical fork of 2 or 3 teeth.

$15 \mathrm{~A} \quad$ Spines on alitrunk, may be restricted to pronotum (may be reduced to a pair of small, unimpressive pronotal spines in Pogonomyrmex), if no thoracic spines, head broad, heavy and highly tuberculate and small blunt spines on head. 6

5B No spines on alitrunk, pronotum smooth or sculpted but not having a pair of small spines; if head heavy and broad, not tuberculate. 
6A Spines on alitrunk variable, but not restricted to one or two pairs of pronotal spines (Figure 25). 7 6B Spines on alitrunk restricted to one (usually) or two pairs of pronotal spines which may be quite small (Figure 26).

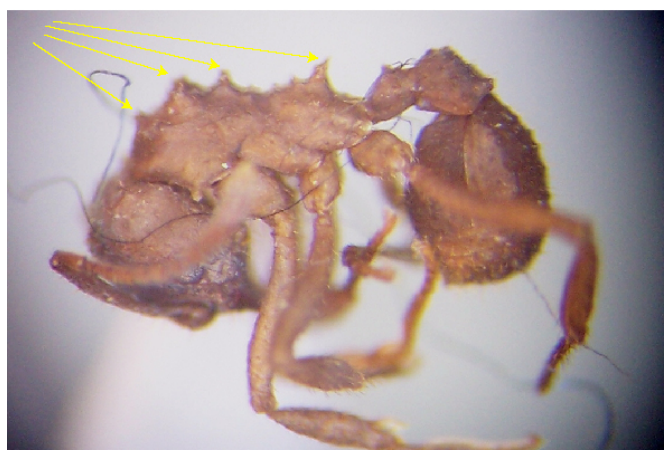

Figure 25. Multiple pairs of spines on alitrunk.

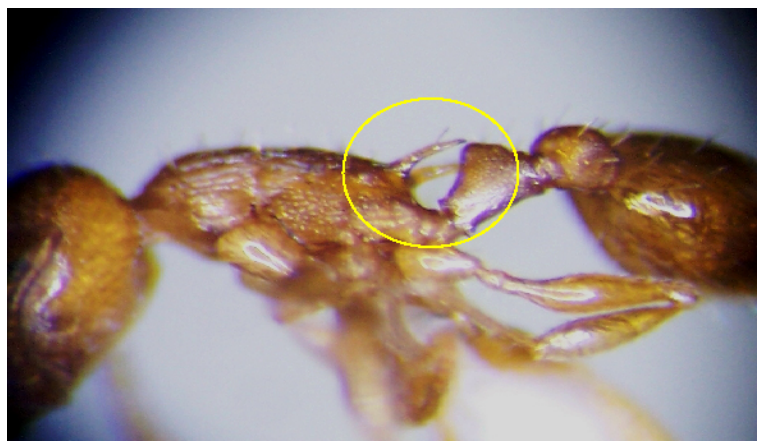

Figure 26. A single pair of pronoteal spines on alitrunk.

67 N Neither bases of antennae nor bases of mandibles visible in full face view (Figure 27). Cephalotes 7B Bases of both antennae and mandibles visible in full face view (Figure 28). Trachymyrmex

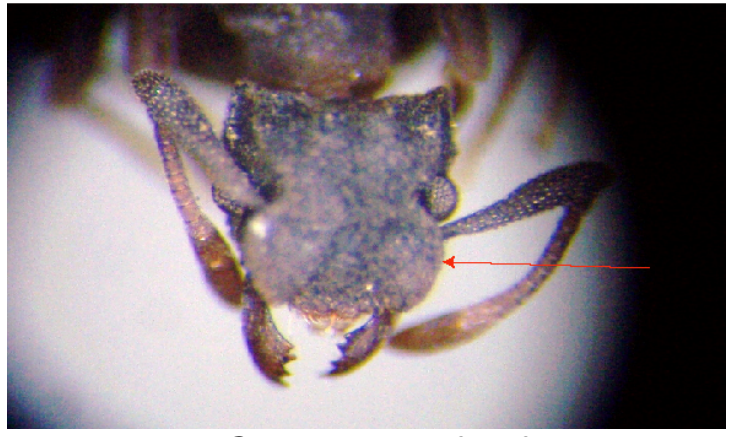

Figure 27. Cephalotes, full face showing the greatly expanded frontal lobes covering bases of antennae and mandibles.

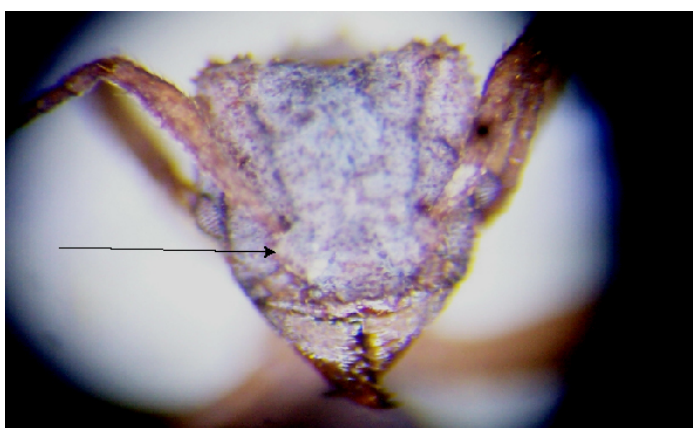

Figure 28. Trachymyrmex, full face, showing that the bases of the antennae and mandibles are not hidden by greatly expanded frontal lobes.

$6 \quad 8$ A Antenna with a distinct club having 2-4 segments. 9

8B Antenna may have up to 4 enlarged segments but there is no distinct club. ........................................................ 18 
$8 \quad 9 \mathrm{~A}$ Postpetiole attaches to anterior dorsal surface of first gastral segment (Figure 29); in profile dorsum of gaster nearly flat and ventral profile strongly convex; in dorsal view gaster heart-shaped.

9B Postpetiole attaches lower on first gastral segment; dorsal profile of gaster usually convex; in dorsal view gaster not heart shaped. 10

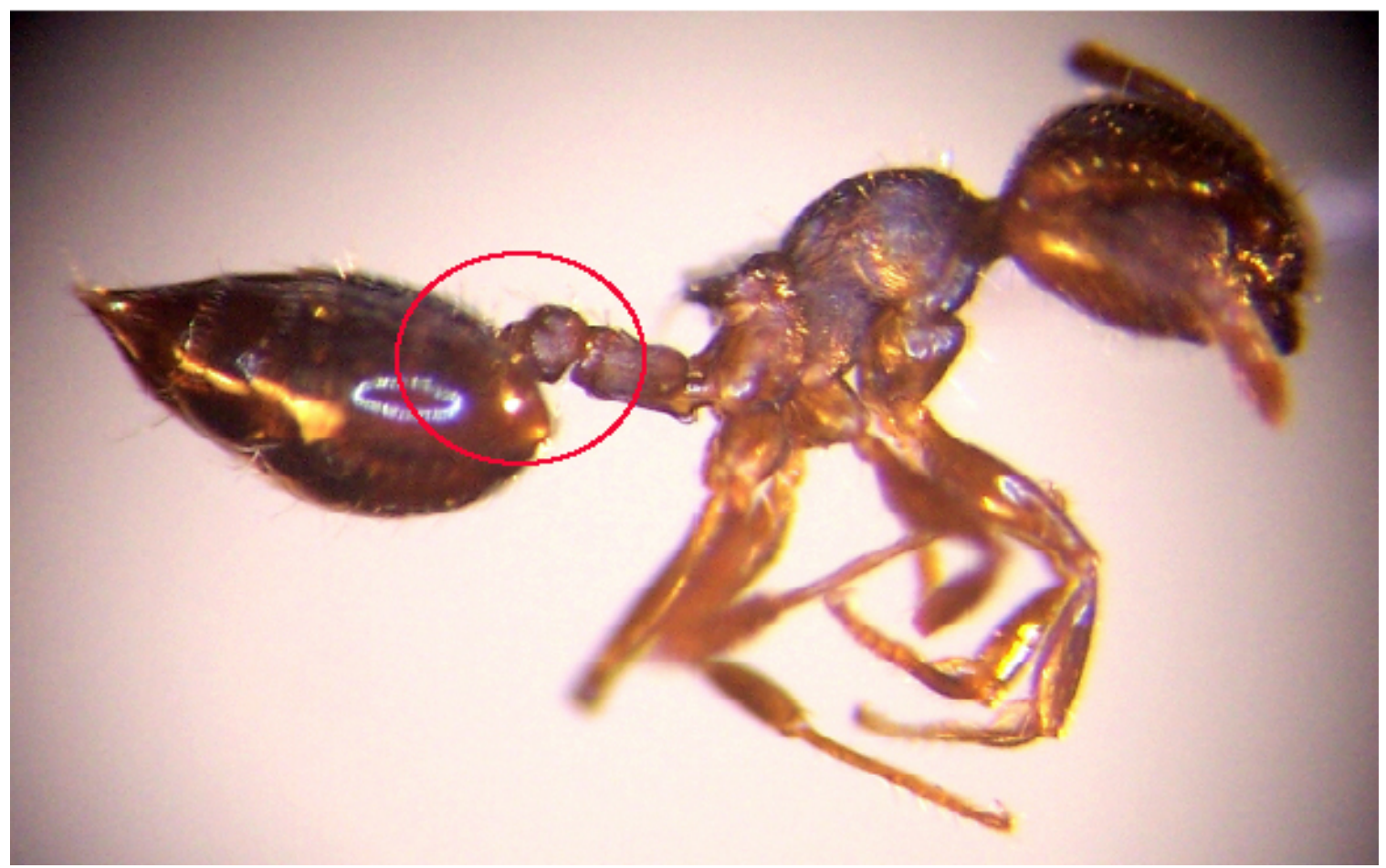

Figure 29. Postpetiole attaching to the dorsal surface of the first gastral segment.

$910 \mathrm{~A}$ Antennal club composed of 2 segments; frontal carina extending almost to posterior margin of head. Wasmannia 10B Antennal club composed of 3-4 segments; frontal carina present or absent but not extending almost to posterior margin of head.

$10 \quad 11 \mathrm{~A}$ A single pair of pronotal spines; eyes large or small; petiole with a peduncle but may be short (Figure 30 ). 11B Two pairs of pronotal spines; eyes small and inconspicuous; petiole with no peduncle (Figure 31). Myrmecina 


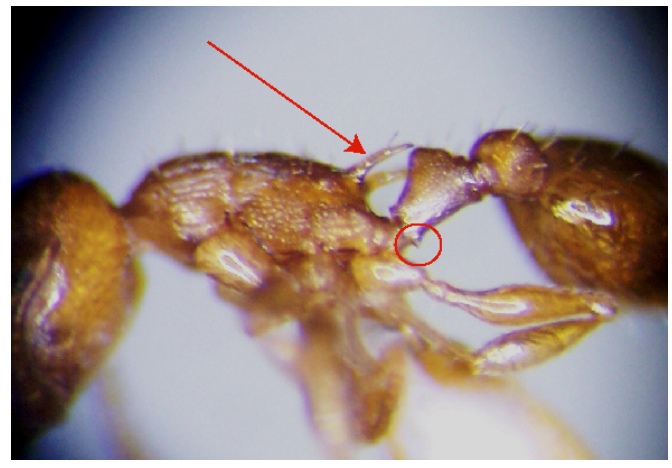

Figure 30. Arrow indicates a single pair of pronotal spines and that the petiole has a short peduncle. The circle indicates the presence of an anteroventral tooth on the peduncle.

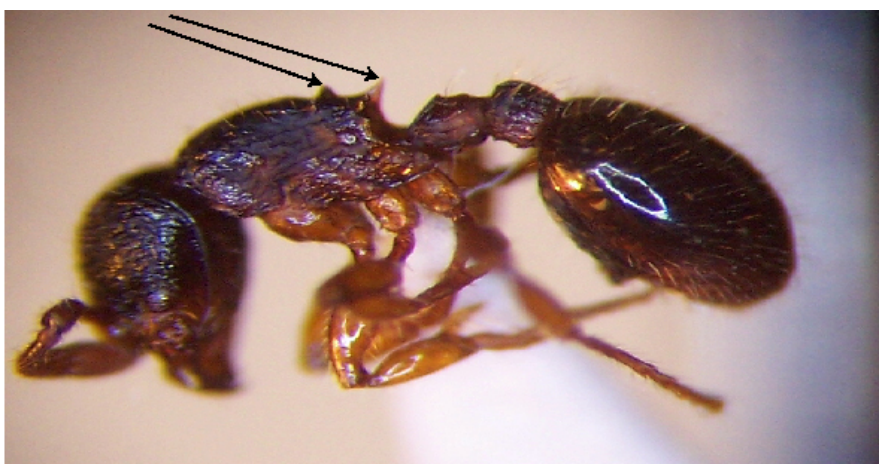

Figure 31. Arrows indicate presence of two pairs of pronotal spines. No peduncle can be seen connecting the petiole to the alitrunk.

11 12A Peduncle with an anteroventral tooth (Figure 30); metanotal impression weak or absent.

12B Peduncle lacking an anteroventral tooth; metanotal impression present or absent, may be clearly defined.

$1213 \mathrm{~A}$ Hind leg with pectinate apical tibial spurs; scape abruptly curved or bent at base. Myrmica 13B Apical tibial spurs of hind leg absent or simple; scape more or less straight but not bent near base. or Macromischa (in part)*

12 14A Antennal club as long or longer than the rest of the funiculus; mandible with two enlarged apical teeth, third tooth smaller than fourth; metanotal impression distinct. Pheidole 14B Antennal club not as long as the rest of the funiculus; mandible various but lacking two enlarged apical teeth; metanotal impression may be absent, weak or distinct.

$14 \quad 15 \mathrm{~A}$ Eye small; body heavily rugulose; clypeus with two carinae that do not form teeth on the outer margin. Stenamma 15B Eyes normal to large; body not heavily rugulose; clypeus may have a median carina but not a pair. 16

$1516 \mathrm{~A}$ Dorsal surface of head and alitrunk lacking erect hairs; when metanotal impression present it is usually not weak. ......... Cardiocondyla 16B Dorsal surface of head and alitrunk with short, stout, blunt, erect hairs; metanotal impression weak or absent. 
$1617 \mathrm{~A}$ Lateral part of clypeus forms a raised, sharp rim in front of antennal insertion; sting with apicodorsal lamellate appendage projecting at an angle to long axis.

Tetramorium (in part)

17B Lateral margin of clypeus not forming a raised sharp rim in front of antennal insertion; sting lacking such an appendage. Leptothorax, Temnothorax or Macromischa (in part)*

$8 \quad 18 \mathrm{~A} \quad$ Lateral part of clypeus forms a raised, sharp rim in front of antennal insertion; sting with apicodorsal lamellate appendage projecting at an angle to long axis. ................................... Tetramorium (in part) 18B Lateral margin of clypeus not forming a raised sharp rim in front of antennal insertion; sting lacking such an appendage.

18 19A Metanotal impression distinct; no psammophore present; mid and hind leg tibial spurs simple or absent. ............... Aphaenogaster (in part) 19B Metanotal groove not impressed; psammophore present on underside of head (Figure 32); mid and hindleg tibial spurs pectinate. Pogonomyrmex

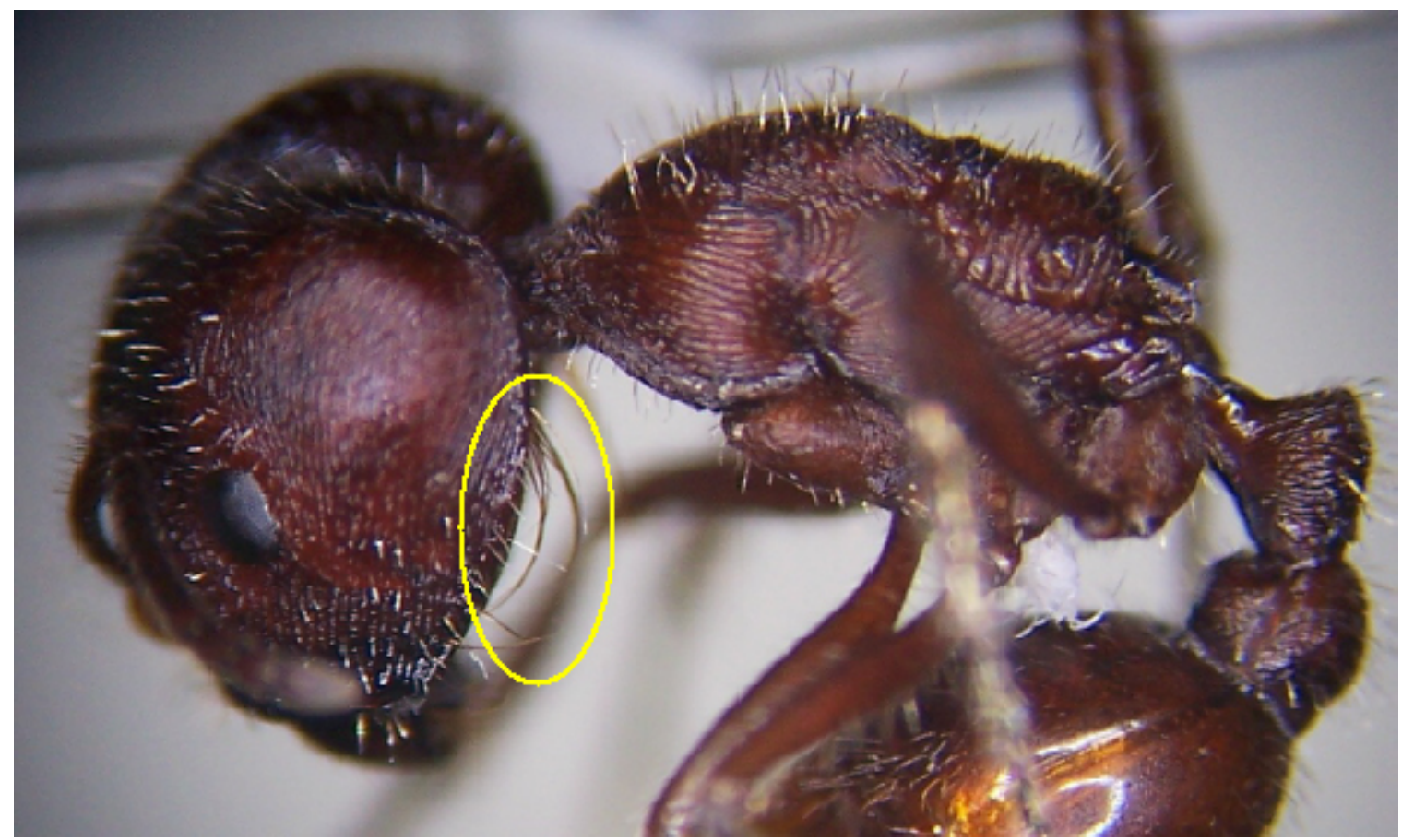

Figure 32. Psammophore visible on underside of head.

520 Antenna with 3 segments in club. 21 20B Antenna may have enlarged terminal segments but not a well defined club.

$2021 \mathrm{~A}$ Anterior margin of clypeus with pair of teeth and an unpaired median seta projecting anteriorly over the mandible (Figure 33). 
21B Anterior margin of clypeus with pair of teeth but if large setae are present between these teeth the setae are paired.

Xenomyrmex

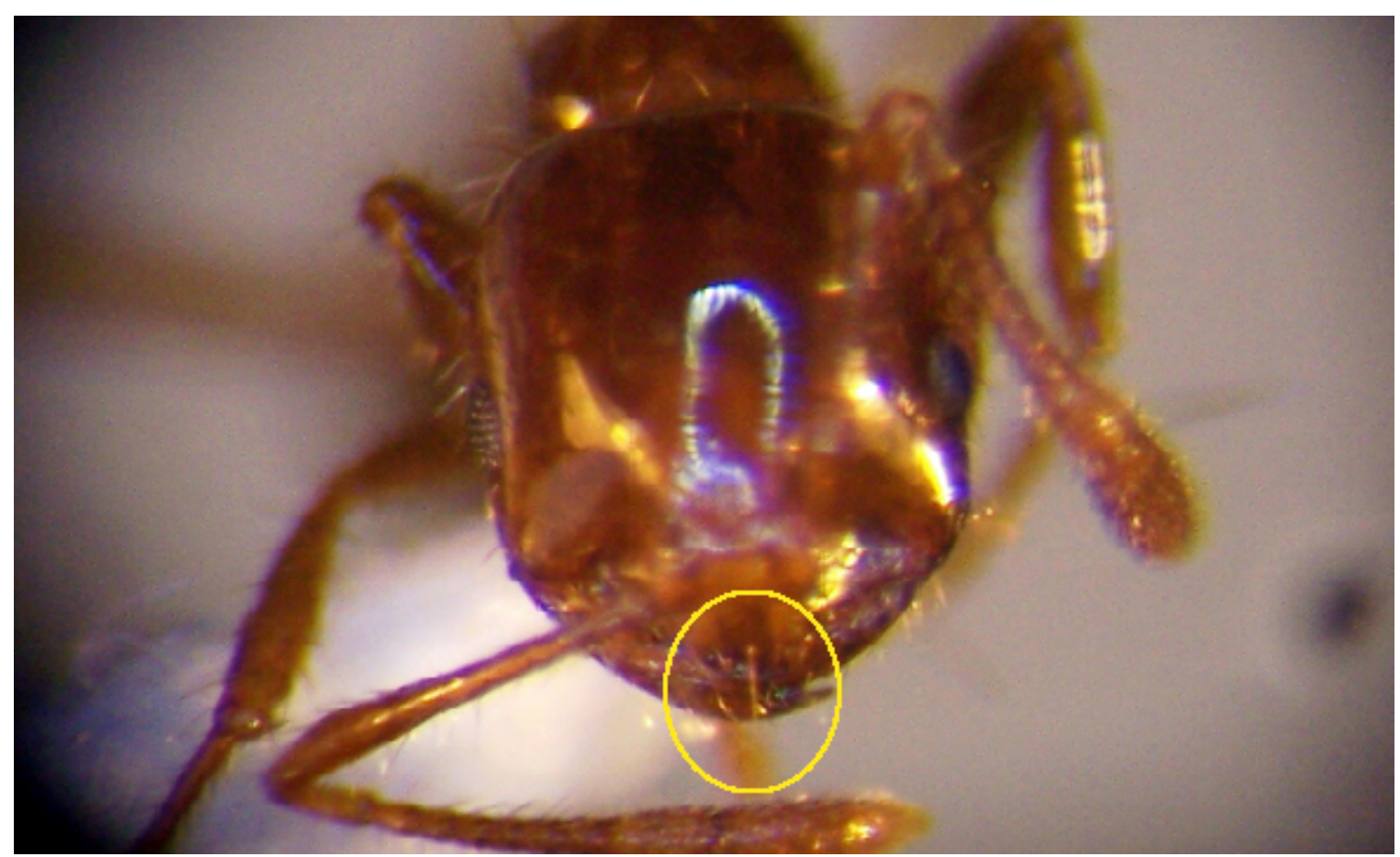

Figure 33. Monomorium, full face, showing the unpaired seta overhanging the mandibles from the central margin of the clypeus.

20 22A Frontal carinae moderately to strongly expanded laterally (and often forward) forming lobes that may cover most are all of the cheeks when seen from a full face view (Figure 34); scrobe strongly developed, extending to posterior margin of head. ..................... Cyphomyrmex 22B Frontal carinae present but not laterally expanded, cheeks and antennal insertions visible in full face view (Figure 35); scrobe absent or poorly developed. Aphaenogaster (in part) 


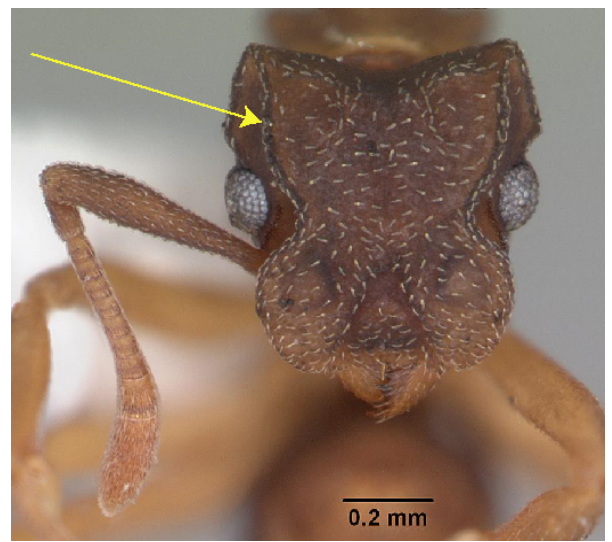

Figure 34. Cyphomyrmex, full face, showing the greatly expanded frontal carinae. [Photographer April Nobile. Copyright 2005 California Academy of Sciences, used with permission.]

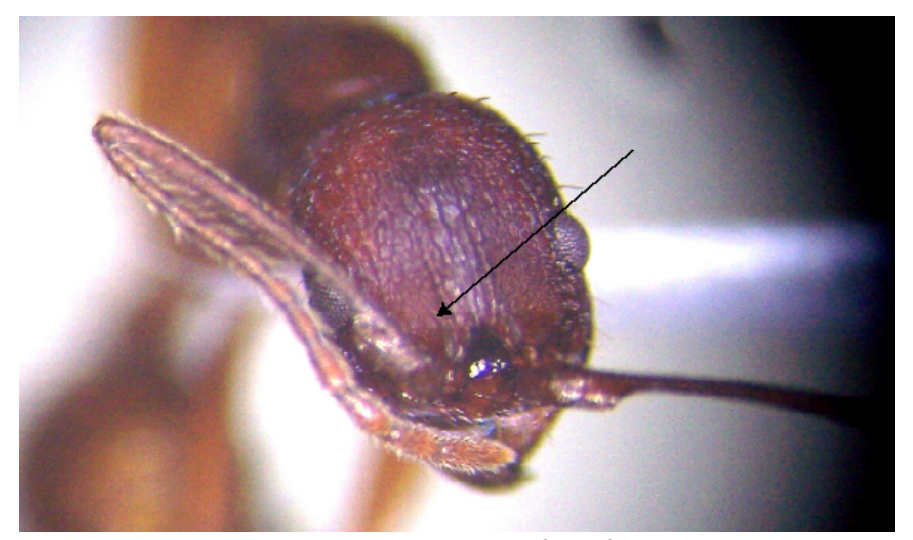

Figure 35. Aphaenogaster, full face, showing the small, unexpanded frontal carinae.

* Leptothorax, Temnothorax or Macromischa - Temnothorax and Macromischa are sometimes treated as separate genera and sometimes as synonyms or subgenera of Leptothorax. 
WSRC-STI-2006-00220

Revision 0

\section{Key to the Local Ponerine Ants}

1A Mandibles long and linear with 2 or 3 apical teeth arranged in a vertical series. ........................................................ 2

1B Mandibles otherwise . ...................................... 3

$12 \mathrm{~A}$ Top backside of head with pair of apophyseal lines converging at top to form a distinct, sometimes shallow, groove in upper part of front of head; gaster lacks slight constriction between first and second segment. Odontomachus 2B Top backside of head with no such pair of apophyseal lines converging at top; gaster having slight constriction between first and second segment. Anochetus

$13 \mathrm{~A}$ Mandible with a small pit-like depression on the dorsolateral surface near the insertion (best seen from below and to side of mandible); eyes small; mid and hind legs with two apical tibial spurs, one pectinate and the other smaller and simple. Cryptopone 3B Mandible lacking such a pit; eyes large or small; tibial spurs single or paired.

34 Subpetiolar process with an anterior, circular fenestra and a pair of small retrorse teeth. Ponera 4B Subpetiolar process present or absent, but if present lacking the fenestra and the pair of small retrose teeth. 5

$45 \mathrm{~A} \quad$ Apex of gaster bent downward so that the apex points forward (may not be quite so curved in some specimens). ............................ 6 5B Apex of gaster not strongly curved forward under the body. ........ 7

$56 \mathrm{~A}$ Antennal club greatly expanded; frontal carinae fused together to form a single vertical plate. Discothyrea 6B Antenna with somewhat enlarged apical segments but not a greatly enlarged club; carinae raised but not fused and vertical. ....... Proceratium

$5 \quad 7 \mathrm{~A} \quad$ Petiole thick, low and rectangular, petiole and first gastral segment separated dorsally and laterally by only a constriction Figure 36); eyes very small. .......................................................... 8 7B Petiole various but not as above and more broadly separated from the first gastral segment (Figure 37); eyes large or small. 


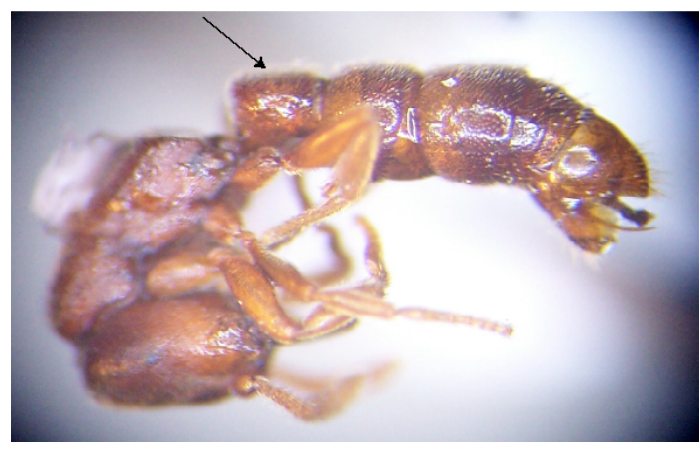

Figure 36 . Thick, low petiole broadly joined to the first gastral segment.

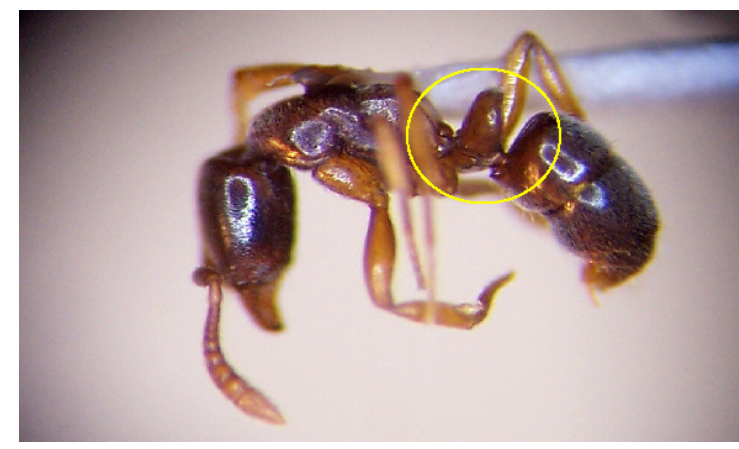

Figure 37. More typical petiole with narrow attachment to the first gastral segment.

$7 \quad 8 \mathrm{~A} \quad$ Mandible long and linear with a row of bidenticulate teeth on the inner border (Figure 38). Amblyopone 8B Mandibles short and narrow with three apical teeth. Prionopelta

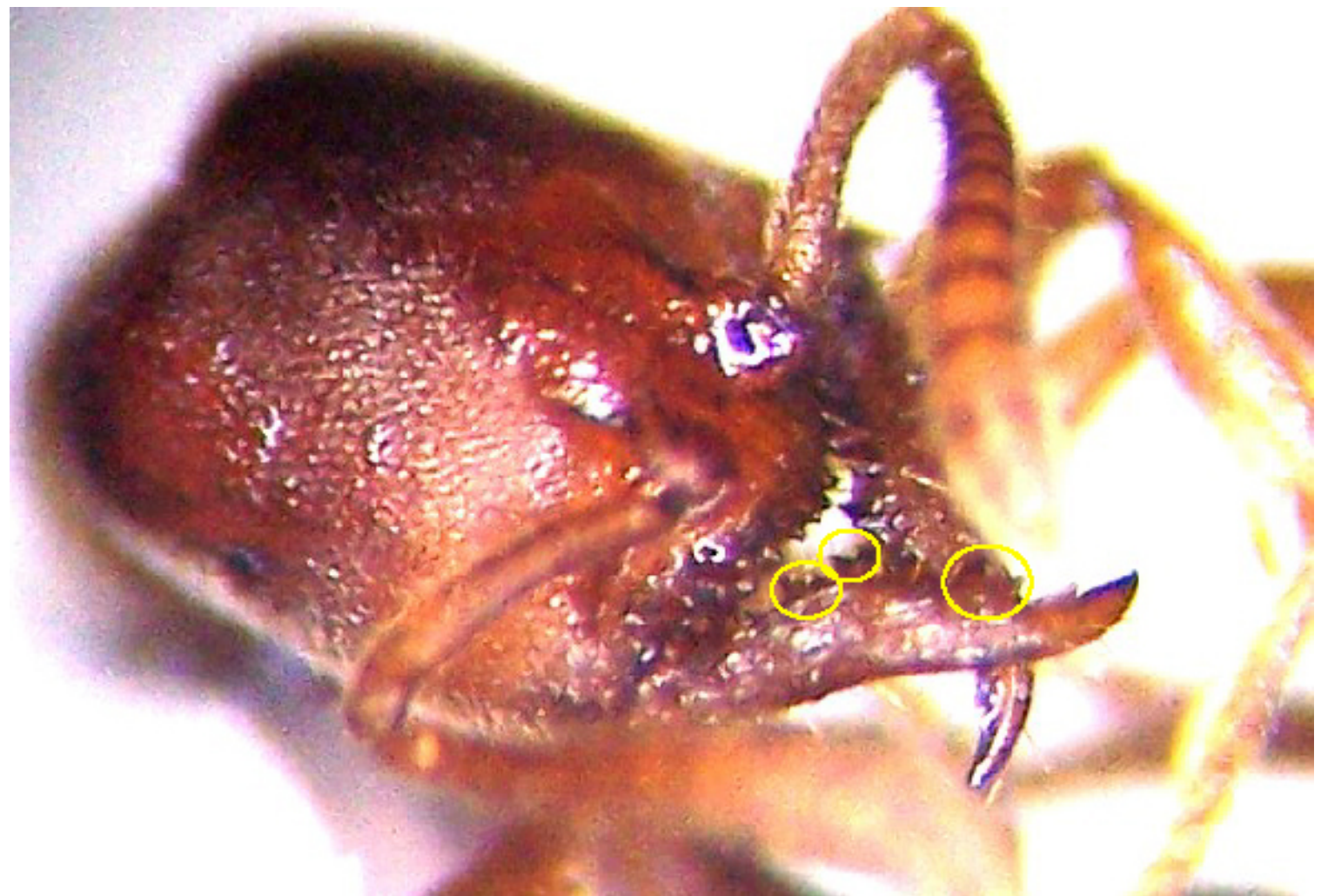

Figure 38. Mandibles of Amblyopone showing at least three bidenticulate (two pointed) mandibular teeth.

7 9A Tibia of mid and hind legs with a single apical spur. 10

9B Tibia of mid and hind legs with a pair of apical spurs. 
$9 \quad 10 \mathrm{~A}$ Eye very small, located distinctly ahead of midlength of head; tarsal claws simple. ................................................ Hypoponera 10B Eye moderate sized, may be fairly high on head; tarsal claw on first leg having a subapical tooth. Gnamptogenys

$9 \quad 11 \mathrm{~A}$ Antennal insertions close together, separated by less than the diameter of a single socket; anterior margin of clypeus sharply triangular and projecting forward; tarsal claws finely pectinate. ............ Leptogenys 11B Antennal insertions more widely separated; anterior margin of clypeus various but not usually sharply tiriangular and projecting forward; tarsal claws simple or with a submedian tooth.

11 12A Frontal carinae converge posteriorly and anteriorly flare out to form lateral lobes that conceal the antennal insertions (full face view). Pachycondyla 12B Frontal carinae well separated and subparallel posteriorly, anterior frontal lobes and antennal insertions well separated by a triangular or broadly rounded posterior extension of the clypeus. Platythyrea 


\section{References}

Basset, Y., J.F. Mavoungou, J.B. Kikissa, O. Missa, S.E. Miller, R.L. Kitching, and A. Alonso. 2004. Discriminatory power of different arthropod data sets for the biological monitoring of anthropogenic disturbance in tropical forests. Biodiversity and Conservation 13:709-732.

Bolton, B. 1994. Identification Guide to the Ant Genera of the World. Cambridge, MA: Harvard University Press. 222 pp.

Deyrup, M. 2003. An updated list of Florida ants (Hymenoptera: Formicidae). Florida Entomologist 86:43-48.

Deyrup, M. A., C. Johnson, G.C. Wheeler, and J. Wheeler. 1989. A preliminary list of the ants of Florida. Florida Entomologist 72:91-101.

Graham, J.H., H. Hughie, R. Long, J. Nutter and J. Kimball. 2004a. The ants of Fort Benning, Georgia. http://fsweb.berry.edu/academic/mans/jgraham/AntsBenning.pdf

Graham, J.H., H.H. Hughie, S. Jones, K. Wrinn, A.J. Krzysik, J.J. Duda, D.C. Freeman, J.M. Emlen, J.C. Zak, D.A. Kovacic, C. Chamberlin-Graham and $\mathrm{H}$. Balbach. 2004b. Habitat and the diversity and abundance of ants (Formicidae) in the Southeastern Fall-Line Sandhills. Journal of Insect Science 4:30, $15 \mathrm{pp}$. insectscience.org/4.30

Ipser, R.M., M.A. Brinkman, W.A. Gardner and H.B. Peeler. 2004. A survey of ground-dwelling ants (Hymenoptera: Formicidae) in Georgia. Florida Entomologist 87(3):253-260.

Mackay, W. and E. Mackay. Date uncertain. Ants of North America. http://www3.utep.edu/leb/antgenera.htm

McGown, J. Date uncertain. Formicidae of Mississippi and Alabama. http://www.msstate.edu/org/mississippientmuseum/Researchtaxapages/F ormicidaehome.html

Oliver, I. and A. J. Beattie. 1996a. Invertebrate morphospecies as surrogates for species: a case study. Conservation Biology 10: 99-109.

Oliver, I. and A. J. Beattie. 1996b. Designing a cost-effective invertebrate survey: a test of methods for rapid assessment of biodiversity. Ecological Applications 6:594-607. 
Plowes, N.J.R. and R. Patrock. 2000. A Field Key to The Ants (Hymenoptera, Formicidae) found at Brackenridge Field Laboratories, Austin, Travis County, Texas. http://www.utexas.edu/research/bfl/species/antkey.pdf

Van Pelt, A. and J.B. Gentry. 1985. The ants (Hymenoptera: Formicidae) of the Savannah River Plant, South Carolina. Department of Energy, Savannah River Plant National Environmental Research Park, Publication SRONERP-14, 56 pp. 


\section{Glossary}

Acidophore - opening of the formic acid projecting system peculiar to, and diagnostic of, ants of the subfamily Formicinae.

Alitrunk - the second visible segment of the ant body behind the head; it is composed of the three segments of the true thorax plus the propodeum which is the first abdominal segment that, in ants, is fused to the thorax.

Anteroventral - adjective describing a direction vectoring both anteriorly and ventrally.

Apex - the tip or most distal part.

Apical fork - having a dichotomous branch at the apex, referring to the branching of the tip of the mandible in some ants.

Apical mandibular tooth - the tooth formed at the tip of the mandible.

Apical spur - a spur located at the apex of the tibia.

Apicodorsal lamellate appendage - a flattened or ribbon-like appendage that projects at an angle to the long axis of the sting and is located near the apex of the sting in the genus Tetramorium.

Apophyseal - having to do with an external ridge or visible external line that indicates internal muscle attachment points.

Carina (pleural carinae) - a keel-like structure.

Club - a noticeably expanded group of distal segments of the antennae

Clypeus (adjective clypeal) - the anteriormost dorsal sclerite or plate of the head immediately in front of the frontal sclerite and separated from it by a suture.

Coxa - the first, most proximal segment of the leg in arthropods.

Edentate - lacking teeth

Fenestra (pleural fenestrae) - a translucent thin spot in the cuticle or exoskeleton.

Foveolate punctures - small pit-like depressions in the integument.

Frontal carina - a paired (usually) keel-like structure on the frontal sclerite or plate of the head, usually starting near the insertion of the antennae 
Frontal lobes - expanded edges of the frontal sclerite or plate of the head that, when well developed, may hide the bases of the antennae and the insertions of the mandibles from view in full face view.

Funiculus - the distal segments of the antenna, essentially all segments other than the basal segment (the scape).

Gaster - the enlarged portion of the abdomen past the waist comprised of abdominal segments 3-7 in ants with only one waist segment (the petiole) and segments 4-7 in ants with two waist segments (the petiole and the postpetiole).

Helcium - a small structure articulating ventrally between the petiole and the postpetiole or the gaster, visible without dissection only in certain groups.

Hypopygium - the lower plate of the last $\left(7^{\text {th }}\right)$ abdominal segment.

Hypostoma -the area of cuticle immediately behind the buccal cavity and forming its posterior margin.

Insertion - where an appendage attaches to the body.

Maxillary palp - paired sensory appendages attached in the buccal cavity composed of 0-6 segments and visible in ventral view.

Mesonotum - the dorsal plate covering the mesothorax and which is often fused to the pronotum which covers the dorsal surface of the prothorax.

Metanotal impression or groove - a groove or depression marking where the plate covering the metathorax (the metanotum) has fused to the mesonotum or the fused plates of the mesonotum and pronotum.

Metapleural gland - a gland that opens onto the posteroventral corner of the alitrunk, the gland itself is most visible as a swelling in the posterior sides of the alitrunk; the pore may be simple or marked by guard setae.

Metapleuron - the plate covering the posterior portion of the alitrunk which has the pore serving the metapleural gland.

Ocellus (pleural ocelli) - a simple eye having only one facet.

Ommatidium (plural ommatida) - a single optical component of a compound eye

Palp - a sensory appendage, there are two pairs in the mouth region, the maxillary palps and the labial palps. 
Palp formula - a standardized formula for indicating numbers of segments in each palp, a formula of 6,4 indicates that there are 6 segments in the maxillary palp and 4 in the labial palp; formula values range from 0,0 to 6,4

Pectinate - having teeth and being comb-like

Peduncle - the relatively narrow anterior portion of the petiole, the length is variable and it may be absent.

Petiole (adjective petiolar) - the first (or only) separate segment between the alitrunk and the gaster.

Postpetiole - when there are two isolated segments between the alitrunk and the gaster this is the posterior segment.

Preapical - refers to being just before the apex.

Promesonotal suture - the suture or groove running across the dorsal alitrunk marking the juncture between the pronotum and the mesonotum; may be absent when the pronotum and mesonotum are completely fused.

Propodeal declivity - the sloping posterior surface of the propodeum.

Propodeal spiracle - spiracle opening onto the side of the propodeum.

Propodeum - the first abdominal segment which has fused to the thorax to form the alitrunk.

Psammophore - a basket-like series of long and usually stout, curved setae on the ventral surface of the head used by some ants to carry sand grains.

Pygidium - the upper plate of the abdominal segment 7 ; the terminal visible dorsal plate of the gaster.

Reflected - turned backward, often in a u-curve.

Retrorse - bent backward or downward.

Rugulose - having fine wrinkles, striations or corrugations.

Scape - the elongated basal segment of the antenna.

Scrobe - a groove, either above or below the eye, that receives the folded antenna 
Seta (pleural setae) hair-like projections from the cuticle.

Sternite - exoskeleton plates from the ventral surfaces of an insect.

Submedian - near but not at the middle point.

Subpetiolar process - a process on the anteroventral portion of the petiole or peduncle which, when present, may be of several different forms.

Sulcus (pleural sulci) - a groove or crevice marking the boundaries between exoskeleton plates.

Tarsus (adjective tarsal) - the five apical segments of the leg which articulate with the tibia.

Tergite - exoskeleton plates from the dorsal surfaces of an insect.

Tibia - the fourth segment of an arthropod leg (counting from the body distally). 